\title{
MODEL PEMBELAJARAN BERBASIS KEARIFAN LOKAL (LOCAL WISDOM) PADA USIA KANAK-KANAK AWAL
}

\author{
Ruliana Fajriati' ${ }^{1}, \mathrm{Na}^{\prime}{ }^{\prime} \mathbf{i m a h}^{2}$ \\ Fakultas Ilmu Tarbiyah dan Keguruan, UIN Sunan Kalijaga Yogyakarta ${ }^{1}$ \\ Fakultas Ilmu Tarbiyah dan Keguruan, UIN Sunan Kalijaga Yogyakarta ${ }^{1}$ \\ Email: rulianafajriati@gmail.com ${ }^{1}$, Email: drnaimah24@ gmail.com ${ }^{2}$ \\ Fajriati, Ruliana,. Na'imah. (2020). Model Pembelajaran Berbasis Kearifan Lokal (Local Wisdom) Pada \\ Usia Kanak-Kanak Awal. Jurnal Pelita PAUD, 4(2), 156-160. \\ doi: https://doi.org/10.33222/pelitapaud.v4i1.956
}

Diterima:09-05-2020

Disetujui: 30-05-2020

Dipublikasikan: 05-06-2020

\begin{abstract}
Abstrak: Penelitian ini bertujuan untuk mengetahui implementasi model pembelajaran berbasis kearifan lokal (local wisdom). Dalam penelitian ini penulis menggunakan metode penelitian deskriptif kuantitatif. Rumusan masalah penelitian ini yaitu bagaimana implementasi model pengembangan pembelajaran berbasis kearifan local (local wisdom) pada usia kanak-kanak awal? Penelitian ini dilaksanakan di TK Nasyithatun Nisa. Masa kanakkanak awal berada pada rentang usia 2 hingga 6 tahun yang merupakan masa penutup masa bayi dimana pada usia tersebut ketergantungan secara praktis sudah terlewati, diganti dengan tumbuhnya kemandirian dan berakhir disekitar usia sekolah dasar. Begitu juga dengan tugastugas perkembangan anak di usia ini perlu di stimulus agar mencapai kemandirian anak pada tahap usia selanjutnya. Sekolah juga perlu melaksanakan pengembangan pembelajaran sebagai bentuk mengoptimalkan pendidikan pada anak usia dini salah satunya dengan mengembangkan pembelajaran berbasis kearifan budaya lokal. Adapun dari hasil penelitian ini yaitu TK Nasyithatun Nisa telah memperkenalkan unsur budaya yaitu pakaian adat, lagulagu, tarian dan makanan khas Melayu Riau.
\end{abstract}

Kata kunci: kanak-kanak awal, kearifan lokal

Abstract: This study aims to determine the implementation of learning models based on local wisdom. In this study the authors used a descriptive quantitative research method. The formulation of the problem of this research is how is the implementation of the development model of learning based on local wisdom in early childhood? This research was conducted at Nasyithatun Nisa Kindergarten. Early childhood is in the age range of 2 to 6 years which is the closing period of infancy where at that age the practical dependency has been passed, replaced with the growth of independence and ends around the elementary school age. Likewise with the tasks of child development at this age need to be stimulated in order to achieve child independence at a later stage of age. Schools also need to implement the development of learning as a form of optimizing education in early childhood, one of which is by developing learning based on local cultural wisdom. As for the results of this study, Nasyithatun Nisa Kindergarten has introduced cultural elements, namely traditional clothing, songs, dances and Riau Malay special foods.

Keywords: early childhood, local wisdom 


\section{PENDAHULUAN}

Salah satu hak manusia yang harus diberikan adalah pendidikan. pada zaman modern ini orang tua seharusnya sadar bahwa pendidikan merupakan salah satu kebutuhan pokok yang tidak bisa di tawar-tawar. Setiap anak yang lahir di bumi pada dasarnya memiliki beraneka ragam bakat yang berbeda-beda. Oleh sebab itu, orang tua diharapkan lebih aktif dan kreatif dalam memberikan stimulusstimulus sehingga anak tumbuh dan berkembang secara normal, baik dari segi fisik, daya piker, daya cipta, sosial-emosional, bahasa dan komunikasi.

Masa kanak-kanak merupakan masa yang penting dalam perkembangan hidup manusia karena masa kanak-kanak merupakan masa paling awal dalam rentang kehidupan yang akan menentukan perkembangan pada tahaptahap selanjutnya. Pada tahap perkembangan anak usia prasekolah ini, anak mulai menguasai berbagai ketrampilan fisik, bahasa, dan anak pun mulai memiliki rasa percaya diri untuk mengeksplorasi kemandiriannya.

Secara luas diketahui bahwa masa kanakkanak dibagi menjadi dua periode, yaitu masa kanak-kanak awal dan masa kanak-kanak akhir (Masganti, 2015). Periode awal berlangsung dari umur dua hingga enam tahun, sedangkan periode akhir dari umur enam tahun hingga tiba saatnya anak matang secara seksual. Secara garis besar proses perkembangan manusia terdiri dari proses biologis, kognitif, dan sosial emosional.

Model pembelajaran untuk anak di masa kanak-kanak awal perlu dikembangkan agar mencapai tujuan pendidikan yang diharapkan. Adapun salah satu model pengembangan pembelajaran pada masa kanak-kanak awal yaitu pembelajaran berbasis budaya local (local wisdom). Pembelajaran berbasis budaya lokal yaitu strategi penciptaan lingkungan belajar dan perancangan pengalaman belajar yang mengintegrasikan budaya sebagai bagian dari proses pembelajaran.

Penelitian yang dilakukan oleh Muzakki dan Puji Yanti Fauziah dengan judul Implementasi Pembelajaran Anak Usia Dini Berbasis Budaya Lokal di PAUD Full Day School mengemukakan bahwa unsur-unsur budaya lokal yang dikembangkan pada pendidikan anak usia dini terdiri dari nilai agama dan moral nilai budaya, permainan, tari dan lagu (Muzakki \& Fauziah, 2015).

Saat ini masih minim lembaga pendidikan PAUD yang memanfaatkan kearifan lokal dalam pembelajaran. Oleh sebab itu perlunya memperkenalkan sejak dini kearifan lokal dan budaya kepada anak. TK Nasyithatun Nisa Teluk Kiambang yang terletak di kecamatan Tempuling, Kabupaten Indragiri Hilir, Provinsi Riau, salah satu lembaga pendidikan anak usia dini yang memanfatkan budaya Melayu sebagai kearifan lokal dalam pembelajaran. Berdasarkan wawancara dengan kepala TK Nasyithatun Nisa, Fifi Icha lestari, S.Pd.I bahwasanya beliau menjelaskan di TK Nasyithatun Nisa telah melaksanakan pembelajaran berbasis kearifan lokal yaitu budaya Melayu Riau. Budaya Melayu merupakan salah satu dari banyak Rumpun Melayu yang ada di nusantara. Mereka berasal dari daerah Riau yang menyebar keseluruh kabupaten-kabupaten yang ada di Riau. Untuk itu dalam artikel ini akan dipaparkan bagaimana implementasi model pengembangan pembelajaran berbasis kearifan lokal (local wisdom) budaya Melayu Riau pada usia kanak-kanak awal dengan rumusan masalah yaitu bagaimana implementasi model pengembangan pembelajaran berbasis kearifan local (local wisdom) pada usia kanak-kanak awal.

\section{METODE PENELITIAN}

Penelitian ini dilakukan di Taman Kanakkanak Nasyithatun Nisa Teluk Kiambang yang terletak di kecamatan Tempuling, Kabupaten Indragiri Hilir, Provinsi Riau. Adapun tujuan penelitian ini untuk mengetahui impementasi model pembelajaran berbasis kearifan lokal (local wisdom) pada masa kanak-kanak awal. Subjek penelitian ini adalah anak TK Nasyithatun Nisa Teluk Kiambang berjumlah 14 anak. Jenis penelitin ini menggunakan penelitian deskriptif dengan pendekatan kualitatif. Informan dalam penelitian ini adalah Kepala Sekolah, Guru Kelas, dan Wali Murid. Teknik pengumpulan data menggunakan observasi, wawancara dan dokumentasi. Data yang sudah terkumpul selanjutnya dianalisis menggunakan data 
pada penelitian ini mneggunakan observasi, wawancara dan dokumentasi. Teknik analisis data menggunakan teknik Interaktif Miles \& Huberman yaitu terdiri dari tiga alur kegiatan yang terjadi secara bersamaan, yaitu: reduksi data, penyajian data, dan penarikan kesimpulan/verifikasi.

\section{HASIL PENELITIAN \\ PEMBAHASAN}

Hasil observasi dan wawancara di TK Nasyithatun Nisa diperoleh informasi bahwa unsur budaya yang dikembangkan dalam pembelajaran yaitu:

\section{Pakaian Adat}

TK Nastithatun Nisa memberikan kesempaatan kepada anak dalam mengenal salah satu pakaian adat Melayu yaitu Baju Kurung Teluk Belang. Berdasarkan hasil observasi yang telah dilaksanakan, sekolah memberikan kesempatan kepada anak dan guru untuk mengenakan Baju Kurung Teluk Belanga setiap hari Jumat. Hal ini bertujuan untuk mengenalkan kepada anak salah satu pakaian budaya Melayu Riau. Selain itu ada juga pakaian adat resmi Melayu Riau yang dikenakan oleh anak-anak ketika acara-acara resmi dan semi resmi, seperti Hari Kartini, Peringatan Sumpah Pemuda, puncak Tema dan lain-lain bahkan dikenakan untuk kostum saat menari.

Kebudayaan merupakan aset bangsa yang harus dijaga serta dilestarikan secara turun temurun dari generasi ke generasi selanjutnya supaya kebudayaan tersebut tidak menghilang ditelan zaman modern yang sangat pesat perkembangannya sat ini. Seperti pakaian adat, tidak sepenuhnya disukung oleh media informasi yang disajikan kepada masyarakat terutama kepada anak-anak (Najahah \& Umar, 2016). Hal tersebut membuat kebudayaan Melayu khususnya pakaian adat nusantara tidak begitu diminati oleh masyarakat luas khususnya generasi anak-anak. Untuk itu di TK Nasyithtun Nisa mengenalkan pakaian adat Melayu melalui pembiasaan dan menjadi seragam yang digunakan setiap hari Jumat.

\section{Lagu-lagu}

Salah satu kegiatan seni yang juga diperkenalkan kepada anak di TK Nasyithatun Nisa yaitu lagu daerah Riau, salah satunya yaitu lagu Soleram. Menurut Rizka Syahfitri selaku guru dan inrorman dalam penelitian ini menyatakan bahwa lagu Soleram ini mengandung makna cinta dan persahabatan, untuk menjaga kehormatan, menjaga harga diri, menjaga malu sebagai budaya, serta menghindari perpecahan antar golongan. Lagu ini dinyanyikan saat kegiatan pembukaan ataupun saat kegiatan penutupan.

Adapun lirik dari lagu Soleram yaitu:

Soleram Soleram

Soleram Anak yang manis

Anak manis janganlah dicium sayang Kalau dicium merah lah pipinya Satu dua Tiga dan empat

\section{Lima enam}

Tujuh delapan

Kalau tuan dapat kawan baru sayang Kawan lama ditinggalkan jangan

Menurut Hidayat (Miranti et al., 2015) lagu yang baik untuk anak usia TK memiliki karakteristik, yaitu: Syair yang tidak terlalu panjang, mudah dihafalkan oleh anak-anak, mengandung edukasi bagi anak, sesuai dunia anak, serta nada yang mudah untuk dikuasai anak. Mindradini (Miranti et al., 2015) menyatakan bahwa melalui metode bernyanyi dapat membuat anak senang dan gembira, mengarah kepada kondisi psikis untuk jiwa yang bahagia, senang akan keindahahn, mengembangkan rasa melalui bernyanyi yaitu berupa ungkapan kata serta nada yang terangkai menjadi lagu, hingga ritmik yang membuat indah akan suasana belajar. Akhirnya anak mengenal dan hafal salah satu lagu tradisional Melayu Riau serta secara psikis anak akan merasakan bahagia dan tidak bosan dalam belajar setiap harinya.

\section{Tarian}

Tarian tradisional budaya Melayu Riau juga diperkenalkan kepada anak di TK Nasyithatun Nisa. Tarian yang diperkenalkan berupa Tari Persembahan. Tari Persembahan merupakan tari yang digunakan untuk pembukaan setiap acara. Misalnya pembukaan acara wisuda anak, pembukaan peringatan hari-hari besar, dan lain-lain.

Menurut Muhammad Ridho (Ridho \& Yohana, 2016) perkembangan tari bukan hanya sekedar kesenian, melainkan sebagai 
P ISSN 2548-6284 E ISSN 2615-0360

Vol. 4 No. 2 Juni 2020

suatu media untuk menyampaikan pesan melalui simbol-simbol kebudayaan pada suatu masyarakat. Pesan-pesan dalam tarian setiap daerah sangat beragam. Misalnya di provinsi Riau yang terkenl dengan Tari Persembahan. Tari ini dilaksanakan dihadapan para tamu yang dihormati. Pada umumnya dilaksanakan di ruang tertutup seperti istana maupun balai pertemuan. Namun dewasa ini Tari Persembahan juga dilaksanakan di ruang terbuka atau lapangan. Tari persembahan sendiri merupakan tari yang diiringi irama lagu Sekapur Sirih dan bisa dilaksanakan oleh anak-anak hingga dewasa. Kerumitan gerakan akan disesuaikan dengan tingkat usia anak.

Haukin (Sutini, 2012) menyatakan tari merupakan suatu ekspresi jiwa manusia yang diubah melalui imajinasi dan diberi bentuk melalui gerak hingga menjadi gerak yang simbolis dan sebagai ungkapan pencipta. Maksudnya tari merupakan penggabungan olah gerak tubuh yang bermakna, indah serta ekspresi yang diungkapkan oleh penampilnya, baik tari dengan irama maupun tanpa irama. Gerak tari dapat meningkatkan kecerdasan kinestetik pada anak, dimana gerak tari memberikan penguatan konsentrasi, keluwesan dan keindahan gerak, bukan hanya pada kinestetik (psikomotor) melainkan dapat memberikan suatu peluang keterampilan tari.

\section{Makanan Tradisional}

Di TK Nasyithatun Nisa juga diperkenalkan makanan tradisional atau kuliner daerah setempat. Roti Jala salah satunya, merupakan makanan khas Melayu Riau yang diperkenalkan melalui kegiatan Cooking Class. Biasanya dilaksanakan pada puncak tema. Anak dan orang tua membuat makanan Roti Jala secara bersama-sama kemudian makan bersama guru-guru di sekolah. Roti jala terbuat dari tepung terigu dan saus durian yang terbuat dari gula merah, santan dan durian.

Kuliner merupakan hasil olahan masakan berupa lauk pauk, makanan atau panganan serta minuman. Menurut Bondan Winarno (Wahritasi, 2017) makanan daerah merupakan makanan serta minuman yang dikonsumsi oleh masyarakat tertentu, dengan cita rasa yang khas yang diterima masyarakat setempat. Melalui pengenalan makanan khas ini akan menambah kelekatan dan kekompakan anak dan orang tua karena masak bersama. Selain itu 6 aspek perkembangan lainnya turut berkembang di masa kanak-kanak awal.

\section{Masa Kanak-kanak Awal}

Masa kanak-kanak awal berada pada rentang usia 2 hingga 6 tahun yang merupakan masa penutup masa bayi dimana pada usia tersebut ketergantungan secara praktis sudah terlewati, diganti dengan tumbuhnya kemandirian dan berakhir disekitar usia sekolah dasar.

Awal masa kanak-kanak dimulai sebagai penutup masa bayi, usia dimana ketergantungan secara praktis sudah dilewati, diganti dengan tumbuhnya kemandirian dan berakhir sekitar usia masuk sekolah dasar.

Adapun sebutan masa kanak-kanak awal oleh para psikolog (Alfiyan \& Rokhmah, 2016) yaitu: (1) Usia kelompok dimana pada masa ini anak anak masih mempelajari dasar-dasar perilaku sosial untuk persiapan bagi kehidupan sosial yang lebih tinggi yang diperlukan untuk menyesuaikan diri saat mereka masuk ke kelas 1. (2) Usia menjelajah untuk explorasi, pada masa ini anak anak cenderung ingin mengetahui keadaan lingkunganya disekitarnya. (3) Usia bertanya, pada masa ini anak cenderung ingin bertanya apa yang mereka anggap tidak tahu kepada orang dewasa. (4) Usia meniru, dimana pada masa ini anak anak ingin meniru toko yang mereka sukai. (5) Usia kreatif, dimana pada masa ini anak anak lebih ingin menunjukkan kreatifitasnya dalam bermain.

Tugas perkembangan pada masa kanak-kanak awal menurut Robert J. Havighurst (Hurlock, 1991) merupakan tugas yang muncul pada saat atau sekitar suatu periode tertentu dari kehidupan individu, yang jika berhasil akan menimbulkan rasa bahagia dan membawa kea rah keberhasilan dalam melaksanakan tugastugas berikutnya. Adapun tugas perkembangan masa kanak-kanak awal yaitu: (1) Belajar keterampilan fisik yang diperlukan untuk bermain. (2) Membina sikap yang sehat (positif) terhadap diri sendiri sebagai seorang individu yang berkembang, seperti kesadaran tentang harga diri dan kemampuan diri. (3) Belajar bergaul dengan teman-teman sebaya sesuai dengan etika moral yang berkembang di masyarakat. (4) Mengembangkan peran sosial sesuai jenis kelamin. (5) Mengembangkan dasar-dasar keterampilan membaca, menulis dan menghitung. (6) Mengembangkan konsep-konsep yang 
diperlukan dalam kehidupan sehari-hari. (7) Mengembangkan sikap objektif baik positif dan negatif terhadap kelompok dan masyarakat. (8) Belajar mencapai kemerdekaan atau kebebasan pribadi sehingga menjadi diri sendiri, mandiri dan bertanggung jawab (Hurlock, 1991). (9) Toilet Training, hakikat tugas yang harus dipelajari anak yaitu buang air kecil dan buang air besar yang bisa diterima secara sosial.toilet training yang berhasil dapat membentuk anak yang berhatihati, dapat menguasai dirinya, mendapatkan pandangan jauh kedepan dan dapat berdiri sendiri. Tentang toilet training Havighurst berpendapat: Toilet training is the first moral training that child received. The stamp of the first moral training that child later character. (10) Belajar kontak perasaan dengan orang tua, keluarga, dan orang lain, menghubungkan diri sendiri secara emosional. (11) Mengembangkan pengetahuan agama sesuai dengan tingkat usianya.

\section{SIMPULAN}

Masa kanak-kanak awal berada pada rentang usia 2 hingga 6 tahun yang merupakan masa penutup masa bayi dimana pada usia tersebut ketergantungan secara praktis sudah terlewati, diganti dengan tumbuhnya kemandirian dan berakhir disekitar usia sekolah dasar. Pada usia ini budaya kearifan lokal perlu dikenalkan pada anak. Pembelajaran yang cocok untuk mengenalkan budaya yaitu pembelajaran berbasis kearifan lokal (local wisdom). Adapun unsur budaya yang dikenalkan di TK Nasyithatun Nisa yaitu pakaian adat, lagu-lagu, tarian dan makanan khas Melayu Riau.

Untuk itu, hasil penelitian ini diharapkan dapat menjadi pedoman bagi guru anak usia dini dalam mengenalkan budaya kearifan lokal di lembaga PAUD.

\section{DAFTAR PUSTAKA}

Alfiyan, A., \& Rokhmah, A. M. (2016). Periodisasi Perkembangan Masa Kanakkanak Awal. Jurnal Psikologi, 152071900009, 1-13.

Hurlock, E. B. (1991). Psikologi Perkembangan Suatu Pendekaatan Sepanjang Rentang Kehidupan (5th ed.). Erlangga.
Jannah, M. (2015). Tugas-Tugas Perkembangan Pada Usia Kanak-Kanak. Gender Equality: International Journal of Child and Gender Studies, 1(2), 87-98.

Masganti. (2015). Psikologi perkembangan anak usia dini. Perdana Publishing.

Miranti, I., Engliana, \& Hapsari, F. S. (2015). Penggunaan Media Lagu Anak-Anak Dalam Mengembangkan Kemampuan Kosakata Bahasa Inggris Siswa Di PAUD. Jurnal Ilmiah Kependidikan, II(No. 2 Juli), 167173.

Muzakki, \& Fauziah, P. Y. (2015). Implementasi pembelajaran anak usia dini berbasis budaya lokal di PAUD full day school. Jurnal Pendidikan Dan Pemberdayaan Masyarakat, 2(1), 39. https://doi.org/10.21831/jppm.v2i1.4842

Najahah, I., \& Umar, E. A. B. (2016). Perancangan Buku Pop-Up Sebagai Media Pembelajaran Tentang Rumah Dan Pakaian Adat Nusantara Di Jawa. Jurnal Seni Rupa, 4(03), 494-501.

Ridho, M., \& Yohana, N. (2016). Konstruksi Makna Tari Persembahan Oleh Penari Padaa Sanggar Tari di Lingkungan Universitas Riau. JOM FISIP, 3(2), 1-16.

Sutini, A. (2012). Pembelajaran Tari Bagi Anak Usia Dini. Cakrawala Dini: Jurnal Pendidikan Anak Usia Dini, 3(2), 1-14.

Wahritasi. (2017). Pelaksanaan Promosi Makanan Tradisional Khas Melayu Di Hotel Furaya Pekanbaru. Jom FISIP, 4(2), 1-11. 